\title{
Escasez extraordinaria y derecho de aguas
}

\author{
Liber Martin* y Mauricio Pinto*
}

El derecho de aguas elaborado en el marco del paradigma decimonónico, considera a la sequía como una situación excepcional que exceptúa de la aplicación de las reglas normales. Sin embargo, la evidencia muestra que la sequía tanto ordinaria como extraordinaria no constituye exclusivamente un extremo hidrológico o climático, sino también un fenómeno económico y social que cambia con el tiempo, y lleva a reformular los presupuestos sobre los que principio y excepción se articulan en el derecho de aguas contemporáneo.

Palabras clave: Escasez, derecho de aguas, emergencia, excepción, discrecionalidad.
Water law from the nineteenth-century paradigm considers drought as an exceptional situation that exempts from the application of normal rules. However, evidence shows that both normal or extreme drought have not only hydrological or climatic causes but also economic and social reasons that change over time. This fact lead to rethink the assumptions on which principle and exception are articulated in contemporary water law.

Keywords: Scarcity, water law, emergency, exception, discretionary powers.

\section{Introducción}

1. Derecho de aguas como derecho a la escasez

El derecho de aguas de aguas elaborado en el marco del paradigma decimonónico, todavía subyacente en la mayoría de las legislaciones de America Latina, considera escenarios normales: de sequía o escasez moderada y de sequía o escasez extraordinaria.

Se repite con insistencia que el derecho de aguas es el derecho de la escasez. Las situaciones de sequía o escasez son consideradas por los

\footnotetext{
* Doctor en Derecho, Investigador de CONICET y Profesor de Derecho Administrativo y Derecho Ambiental y de los Recursos Naturales de la Facultad de Derecho, Universidad Nacional de Cuyo/Universidad de Mendoza. Correo electrónico: libermartin@gmail.com ** Doctor en Derecho, Jefe del Departamento Jurídico del organismo del agua de la Provincia de Mendoza, e Investigador y Profesor de Derecho Ambiental y de los Recursos Naturales en la Universidades Nacional de Cuyo, Mendoza y Aconcagua. Correo electrónico: mpinto@fca.uncu.edu.ar
}

Recibido el 1 de abril y aceptado el 24 de abril de 2015 
estatutos de aguas como estados excepcionales o de emergencia, en contraposición al estado de normalidad en que se gestionan las aguas.

En las geografías desérticas o semidesérticas la escasez o la sequía -tanto normal como extraordinaria- existió siempre, pero es cada vez más evidente que esas condiciones se han modificado no solo desde la perspectiva hidrológica o climática, sino también social, económica y cultural; y en consecuencia, tanto los parámetros para definirla como las reglas para enfrentarla han devenido obsoletas o ineficaces en muchos casos $^{1}$.

La función de la ciencia es cuestionar el modo en que habitual y pacíficamente las cosas son entendidas, justificadas o demostradas, ya sea para comprender sus presupuestos o incluso para sustituirlos, y eso es lo que en esta ponencia nos proponemos.

Lo que se pretende poner en tela de juicio y discutir en este trabajo es: primero, la eficacia de los institutos clásicos para enfrentar la sequía; y en segundo lugar, y con relación a lo anterior, el carácter excepcional de la situación de escasez como justificativo para la suspensión de la aplicación del ordenamiento jurídico tanto como las medidas para enfrentarla; y como resultado de todo ello, la necesidad de replantear algunos presupuestos del derecho actual de aguas.

\section{Escasez, sequía, excepción y emergencia hídrica}

Son varios los conceptos utilizados para referir a la situación de carestía hídrica y el uso de uno u otro no resulta indiferente. La escasez puede ser meteorológica, hidrológica, pero desde el punto de vista antropocéntrico la escasez es siempre económica y social, relativa a determinado contexto de uso y distribución ${ }^{2}$. Sin embargo, no son las definiciones desde el punto de vista técnico, que difieren mucho entre sí, las que interesa indagar en este corto espacio de reflexión y conforme el objetivo propuesto.

Sí es necesario puntualizar la incertidumbre que agrega el considerar la escasez o la sequía no como un concepto exclusivamente técnico o hidrológico ${ }^{3}$, sino a la vez como un concepto jurídico y político. Esto

\footnotetext{
1 El trabajo se circunscribe por tanto a aquellos lugares o sitios donde la sequía o la escasez sea la condición determinante de la conformación del ordenamiento jurídico y se presente con una habitualidad tal que sea susceptible de poner en tela de juicio las reglas predispuestas para condiciones de normalidad.

2 Desde autores como Wittfogel durante el siglo pasado, Worster hasta Swyngedouw en la actualidad, por mencionar tan solo algunos de los más conocidos, han utilizado y difundido este tipo de enfoques. También lo adoptan documentos internacionales como el Programa de las Naciones Unidas para el Desarrollo, Informe sobre Desarrollo Humano 2006.

3 EI DGI Mendoza adopta un criterio según el cual un año es considerado "seco" cuando los valores de derrame están por debajo del $65 \%$ del valor promedio histórico. En cambio,
} 
es que la escasez no puede presentarse como un hecho de la naturaleza vinculado a la falta de precipitaciones o escurrimiento de caudales exclusivamente, sino que constituye a la vez el resultado de un determinado esquema de distribución de las aguas que privilegia unos usos o usuarios a favor de otros.

De allí que no se pueda hablar exclusivamente de una escasez natural o hidrológica, sino también de un verdadero relato de la escasez construido desde el sistema político y social. La sequía está evidentemente vinculada a la escasez, que puede ser ordinaria o extraordinaria. La sequía o escasez extraordinaria es justamente la que justifica la declaración de emergencia hídrica y con ella la excepción del ordenamiento jurídico para posibilitar la superación de la tragedia o catástrofe, como se verá a continuación.

Las vinculaciones son múltiples y no se trata aquí de desentrañar estos conceptos, ni hacer un trabajo de semiología, sino tan solo de ubicar correctamente el problema propuesto.

\section{Escasez ordinaria: mecanismos previstos para su manejo en la legislación clásica}

El derecho clásico de aguas contempló diversos mecanismos para la administración de la escasez, entre los cuales se encuentran aquellos para asignar derechos cuando no hay disponibilidad suficiente (1) y aquellos para distribuir aprovisionar de agua a los derechos ya otorgados en situaciones de escasez o insuficiencia de caudales (2).

\section{Mecanismos para la asignación de derechos de aguas}

a) Regímenes de prioridades. Dentro de los denominados usos especiales, privativos o productivos, para los que se requiere normalmente título administrativo (permiso o concesión), la legislación de aguas, con pocas excepciones, prevé el orden de prioridades a ser tenido en cuenta para el otorgamiento de derechos.

El otorgamiento de derechos de aguas cae normalmente bajo la órbita de la actividad discrecional de las autoridades de aguas que deben atener -sin embargo- los órdenes de prioridades establecidos por la ley. Estos órdenes o sistemas de prioridades pueden ser rígidos (el orden preferencial es fijado en la ley de manera inamovible), flexible (el

será "pobre" cuando el derrame esté entre el 65\% y 85\% por debajo de la media histórica. La DGA de Chile tomaba como criterio dos circunstancias que pueden presentarse de manera simultánea o separada. El nivel de precipitaciones, cuando la acumulación a partir del mes de abril sea inferior al 50 \% del valor medio estadístico; y el de caudales medidos, que consiste en que el caudal medio mensual de los ríos sea inferior al $50 \%$ del caudal de probabilidad de excedencia del mismo mes (Res. DGA N³9 de 1984). 
orden es establecido en cada caso en forma discrecional por la autoridad administrativa) y semiflexible (la ley fija un orden, pero que puede ser alterado de manera fundada).

Los órdenes de prioridades son establecidos normalmente en función de los usos, pero para el caso de solicitudes concurrentes sobre el mismo uso es común que las legislaciones provean otros criterios para priorizar el otorgamiento. Así, sistemas de prioridades como el de la provincia de Mendoza, por ejemplo, prevén un doble e incluso triple orden para el otorgamiento de derechos, donde ante la concurrencia de solicitudes para idénticos usos, en algunos casos la preferencia se establece según la naturaleza jurídica del sujeto solicitante (1. personas públicas, 2. consorcios, asociaciones y cooperativas de usuarios, y 3. personas privadas), para aportar como último criterio la prelación en la presentación de la solicitud (arts. 4/7, Ley N 4035, de aguas subterráneas) ${ }^{4}$; y en otros, si la prioridad por usos no resuelve el problema por ser todas las peticiones sobre idénticos usos, la preferencia se fija según la importancia y utilidad del emprendimiento, y en su defecto por la premura de la solicitud (art. 116 de la LAg. de Mendoza, Argentina) ${ }^{5}$.

La aplicación de estos sistemas en la práctica, sin embargo, no es pacífica y puede ser excepcionada legalmente y/o desvirtuada ilegalmente por las autoridades, o incluso su resolución acorde a derecho puede acarrear tensiones sociales por parte de los intereses que no fueron priorizados, constituyéndose muchas veces también en fuente de conflictos, como ha ocurrido en los casos de Mendoza, Argentina y Perú por citar tan solo algunos de ellos ${ }^{6}$.

b) La cláusula sin perjuicio de terceros. La cláusula sin perjuicio de terceros, reflejo del principio prior tempore, prior iure, constituye una

\footnotetext{
${ }^{4}$ Este sistema previsto para las aguas subterráneas, a diferencia del que seguidamente se refiere en la LAg superficiales, tiene un carácter semiflexible desde, que puede ser excepcionado por resolución fundada de la autoridad, cuando se acreditara fehacientemente que el beneficio económico-social es notoriamente superior al de la solicitud preferente competitiva (art. 8 Ley $N^{\circ} 4035$ ).

5 La legislación peruana confiere prioridad al 1. Uso primario, 2. Uso poblacional, 3. Uso productivo (art. 35), y dentro de los usos productivos al: 1. Agrario: pecuario y agrícola; 2. Acuícola y pesquero; 3 . Energético; 4. Industrial; 5 . Medicinal; 6. Minero; 7. Recreativo; 8. Turístico; y 9. de transporte (art. 43). Ante la concurrencia de solicitudes sobre un mismo uso productivo se preferirá al de mayor interés público, conforme los criterios de: a) mayor eficiencia en la utilización del agua; b) mayor generación de empleo; y c) menor impacto ambiental. En igualdad de condiciones, se prefiere la solicitud más antigua y si fuese imposible resolver mediante esos criterios, finalmente la autoridad resolverá a favor de la solicitud que sirva mejor al interés de la Nación, el desarrollo del país y el bien común (art. 55 Ley de Recursos Hídricos del Perú).

${ }^{6}$ Resulta claro como la falta de publicidad, transparencia, participación y claridad de los procedimientos administrativos de aplicación de los órdenes de prioridades puede operar como fuente de conflictos.
} 
regla básica de solución de conflictos según la cual nuevos derechos de aguas no pueden ser otorgados en detrimento de los derechos constituidos con anterioridad. En otras palabras, ante el conflicto entre dos derechos de aguas, prevalece el otorgado con antelación. Sin embargo, la aplicación estricta y sin modulaciones de esta regla tan antigua como básica puede constituir fuente de conflictos, dependiendo de la estructura de los derechos y la práctica administrativa de cada país.

La cláusula tiene además una funcionalidad diversa desde el plano teórico. Por un lado, denota la neutralidad de la administración ante los conflictos que pudieran tener lugar entre particulares como consecuencia del otorgamiento de los derechos; y por otro, cumple la función de dejar a salvo la responsabilidad estatal por los daños que puedan producir a terceros los derechohabientes; a la vez que importa que el otorgamiento de la prerrogativa lo es sin perjuicio de la existencia de un mejor derecho sobre el mismo objeto normalmente fundado en su precedencia en el tiempo.

La aplicación de esta cláusula ante nuevas necesidades sociales que tensionan con el suministro de derechos otorgados con anterioridad, ha sido desarrollada desde su vertiente materialista, contemplándose en la generalidad de las legislaciones que los derechos otorgados pueden ser revocados para satisfacer necesidades posteriores de usos de mayor interés social si son compensados indemnizatoriamente. En este sentido, por ejemplo, el art. 117 LAg de Mendoza.

c) Mercados de aguas. El agotamiento de la mayoría de las cuencas y acuíferos configura una situación de escasez relativa y ha provocado que los mecanismos normales de asignación de derechos nuevos cedan protagonismo a los mecanismos de reasignación de derechos, tanto los que reposan sobre mecanismos de decisión política estatal como los que lo dejan librado a criterios de mercado.

Especialmente apto se ha mostrado este mecanismo de mercado para resolver conflictos en momentos de escasez o sequía extrema ${ }^{7}$ donde la decisión política hubiera resultado muy difícil y sería percibida como injusta. El mercado ha permitido también una reasignación fluida de los derechos de agua en las áreas en proceso de urbanización ${ }^{8}$; tarea que a través de procedimientos administrativos centralizados habría resultado difícil y conflictiva.

El caso del derecho chileno es elocuente. En Chile, los derechos se otorgan una vez verificados y cumplidos los requisitos de disponibilidad de agua, procedencia legal de la solicitud e inexistencia de perjuicios a

\footnotetext{
7 EMBID IRUJO 2013.

8 PEÑA 1996.
} 
derechos de terceros, sin orden de prelación de usos (arts. 22 y 141 inc. final CAg). A diferencia de la mayoría de las legislaciones, el CAg de Chile no prevé órdenes de prioridades entre usos para el otorgamiento de derechos, ni un orden legal donde el abastecimiento poblacional resulte prioritario, lo que aparece como una potencial fuente de conflicto. Aun en situaciones de escasez, se supone que es el mercado de derechos el marco en el cual deben resolverse tanto la obtención de derechos como los déficits de abastecimiento.

Sin embargo, respondiendo a esa preocupación, la reforma de 2005 incorporó el art. 147 bis al Código de Aguas de Chile estableciendo que el Presidente de la República podrá disponer fundadamente, con informe de la DGA, la denegación parcial de una solicitud de derecho de aprovechamiento cuando sea necesario reservar el recurso para el abastecimiento a la población por no existir otros medios para obtener agua.

2. Mecanismos para la distribución de las aguas o abastecimiento de los derechos

En este apartado, a diferencia del anterior, no se analiza cómo disponer la asignación de derechos de agua frente a eventuales demandas múltiples, sino cómo distribuir el agua entre las demandas concretas que implican los derechos concedidos.

Nuestro propósito es considerar algunos aspectos generales de tal problemática y las instituciones usuales que se regulan, reconociendo que, como se lo ha hecho en relación al caso chileno", el derecho de aguas es en realidad el derecho de la escasez de agua, estando toda su estructura encauzada a su distribución.

a) Prioridad para el abastecimiento de usos de mayor interés social. Casi todas las legislaciones contemplan orden de prioridades para el otorgamiento de derechos, pero muy pocas adoptan unas reglas específicas y claras para el abastecimiento de los derechos en situaciones de escasez, teóricamente excepcional, pero que han devenido la regla en muchos países y lugares. Este tipo de regulaciones -el orden de prioridad del abastecimiento de los derechos- está usualmente contenido, como mucho, en normas de carácter reglamentario, si no librado al criterio exclusivo de la autoridad política del momento.

Sin embargo, sí es un principio general presente en las legislaciones que, como correlato de su carácter público, se confiera una prioridad absoluta a los usos comunes, domésticos o primarios y generales de la población sobre las aguas públicas -e incluso algunas legislacio-

9 Vergara Blanco 1999. 
nes sobre aguas privadas- por sobre los usos especiales, privativos o especiales según la denominación que se adopte ${ }^{10}$.

Luego de la general prioridad que detentan los usos comunes frente a los especiales, las legislaciones pueden prever un orden de prioridades para el abastecimiento de los derechos, que puede o no ser el mismo que el orden de prioridades para el otorgamiento de los derechos.

De hecho, el abastecimiento prioritario de los derechos en situaciones de escasez puede y debiera atender una distribución selectiva no solo entre usos, sino también hacia adentro de cada categoría de uso que, sin embargo, no es común observar en la legislación general. Así por ejemplo, el uso abastecimiento poblacional con prioridad ineludible en todas las legislaciones de la región, con excepción de la chilena -y que en muchos sistemas al ser abastecidos por la misma red incluye varios usuarios industriales-, puede, sin embargo, ser restringido en situaciones de escasez hídrica y ser acotado exclusivamente a las necesidades personales (art. 41 Ley de Recursos Hídricos del Perú).

Dentro del uso riego, se podría privilegiar aquellos cultivos a los que por su naturaleza -ej. cultivos leñosos, árboles- no pudiera interrumpírseles un suministro mínimo sin causar un daño irreparable, a diferencia de otros -como los anuales- cuya interrupción no afectaría más que una cosecha. De igual forma, un sistema que priorice el otorgamiento de derechos para uso agrícola puede, sin embargo, en el orden de prioridades para el abastecimiento, sacrificar algún tipo de cultivo en favor de un uso industrial cuya interrupción pueda tener un costo social y económico muy superior.

\footnotetext{
10 La clasificación de los usos del agua pública en comunes, domésticos y primarios o generales por un lado y en contraposición a ellos los usos especiales privativos o exclusivos ha sido adoptada por la gran mayoría de la legislación de aguas de la región. La diferencia radica en que los primeros son aquellos cuyo objeto principal e inmediato es la satisfacción de necesidades físicas indispensables para la vida, pueden realizarlo todos los hombres por su sola condición de tales, sin más requisito que la observancia de las disposiciones reglamentarias de carácter general dictadas por la autoridad. Esta categoría incluye normalmente el beber, bañarse, lavar ropa, abrevar ganado, regar plantas, navegar, pescar, etc. Se los define como gratuitos, generales y libres y por su naturaleza no implican una disminución o perjuicio sensible de los caudales. En cambio, y por contraposición, los usos especiales suelen ser definidos como aquellos que están dirigidos a producir un aumento en la esfera de acción y el poderío económico del hombre, aunque quizás su elemento más distintivo resulte de la extracción de significativos caudales que impactan sensiblemente en la disponibilidad del recurso para otros usuarios; son onerosos, determinados y requieren del otorgamiento previo de un título administrativo alcanzando usos tales como abastecimiento poblacional, irrigación, industria, minería, energía, etc. Sin embargo, debe tenerse presente que el contenido, la definición y los medios tanto de los usos comunes como especiales pueden variar sustancialmente de acuerdo a cada legislación.
} 
b) La jerarquía/categoría de los derechos. Las legislaciones de aguas también contemplan distintas categorías de derechos de aguas que pueden estar compuestas por múltiples elementos, a saber, legales, de forma de otorgamiento, naturaleza del título, antigüedad, uso o tipo de agua, etc. Uno de los efectos de esa diferente jerarquía es la prioridad que se confiere a unos en detrimento de otros para ser abastecidos en situaciones de escasez. Así, hay derechos definitivos y eventuales, permisos y concesiones, derechos sobre aguas vivas, sobrantes y de reuso, derechos anteriores y posteriores.

En estos supuestos, el orden de prioridad no está determinado por el mayor interés social que ciertos usos o actividades pueden presentar, sino en relación con la protección de los derechos adquiridos por algunos usuarios, siendo estas regulaciones un lógico resultado del principio prior tempore, prior ius y de la aplicación estricta de la cláusula sin perjuicio de terceros bajo la cual fueron otorgadas ciertas concesiones, lo que constituyen el reflejo del valor seguridad perseguido por las leyes decimonónicas de aguas ${ }^{11}$.

El derecho de aguas de Mendoza, por ejemplo, contempla dos categorías de derechos de aguas bien diferenciadas (definitivos o eventuales), según se hayan otorgado antes o después de la sanción de la Ley de Aguas vigente desde 1884, y/o de la realización del aforo en tanto operación técnico-jurídica prevista en el ordenamiento constitucional que fija el régimen de las concesiones ${ }^{12}$. Esto significa que los derechos definitivos -siempre más antiguos- se abastecen teóricamente con prioridad a los eventuales que están sujetos a la disponibilidad de agua existente luego de haber sido abastecidas las concesiones definitivas.

Pero tal diferenciación legal y teórica no encuentra su fiel reflejo en la práctica, donde, por el contrario, se observa una equiparación relativa entre las concesiones definitivas y eventuales. La teórica prioridad de abastecimiento total que tienen los derechos definitivos por sobre los eventuales, y los eventuales anteriores sobre los posteriores, ha sido dejada de lado por la práctica regulatoria y administrativa, y avalada por la jurisprudencia ${ }^{13}$ que, desconociendo tal principio por razones

${ }_{11}$ El cuño liberal que presentan gran parte de los institutos presentes en las legislaciones de agua, mucho de ellos forjados en el contexto decimonónico, quizás ayude a comprender por qué aunque la generalidad de los regímenes presentan mecanismos de preferencia de suministro basados en la protección propietaria a los derechos adquiridos, han omitido regulaciones análogas en función de los usos de mayor interés social.

12 Resultan concesiones eventuales las otorgadas con posterioridad a la Ley de Aguas (art. 19 y ss. LAg), o las otorgadas con posterioridad en la medida en que no se hubiere producido el aforo de los ríos (art. 194 Const. de Mendoza).

13 Sobre la instrumentación de esta práctica, PINTO 2001, 575. Aunque este régimen contraría el principio distributivo inicial y relativiza la efectividad de la cláusula sin perjuicio de terceros, el mismo ha sido convalidado judicialmente por la Suprema Corte 
materiales -en tanto los tipos de derecho se encuentran intercalados en la realidad física-, de equidad y paz social para evitar conflictos, ha optado por el abastecimiento simultáneo, aunque con volúmenes diferenciales, de ambos tipos de concesiones ${ }^{14}$.

c) La distribución proporcional en turnos. Cuando existen derechos reconocidos u otorgados para el uso del agua, suele establecerse que, frente a una situación de escasez que impida abastecer plenamente el volumen otorgado en el título, el recurso debe distribuirse de manera proporcional entre todos los usuarios conforme los derechos que de$\operatorname{tentan}^{15}$. Con ello, todos los derechos de igual categoría son abastecidos similarmente, aunque de manera deficitaria (ej. arts. 162 a 167 de la LAg. de Mendoza, Argentina). Esta metodología resulta útil en la medida en que los usos respondan a intereses de idéntica jerarquía o mientras la reducción proporcional no desnaturalice los usos que hacen a bienes de mayor jerarquía por afectar sus contenidos esenciales o las prioridades existentes a las que hemos referido.

Este mecanismo previsto como excepcional por la legislación para operar la distribución en situaciones de escasez ha devenido absolutamente normal y ordinario desde hace tiempo en la provincia de Mendoza y en la generalidad de las regiones áridas y semiáridas con desarrollo de sistemas de riego.

\section{Ineficacia de los mecanismos clásicos}

No es difícil constatar luego del repaso efectuado cómo muchos de los mecanismos predispuestos en la legislación para administrar la escasez, han resultado aunque en distinta medida muy difíciles o imposibles de aplicar por muy diversos motivos, es decir, ineficaces.

de Justicia de Mendoza al sostener que "no es repugnante a la sistemática del derecho de aguas mendocino la existencia del derecho eventual equiparado por las leyes anteriores comentadas ( $n^{\circ} 430,712,804$ y 930) al derecho definitivo de riego" (sentencia del 24/03/1977 in re Morales, Ramón R. c/ Departamento General de Irrigación); criterio que ha sido reiterado más recientemente en las sentencia del 11/10/2011 in re Keltisur SA c/Departamento General de Irrigación s/APA, y del 18/10/2011 in re Porolli de Pulenta Liliana Rosa s/APA c/Departamento General de Irrigación.

${ }^{14}$ Este ejemplo deja en claro que en situaciones de escasez una aplicación estricta de la jerarquía de los derechos o de la cláusula sin perjuicio de terceros, si bien procedente y correcta desde el punto de vista legal, puede dar lugar a conflictos y alterar la paz social si no es aplicada con el debido cuidado e información. Las reglas para el abastecimiento preferencial en situaciones de emergencia o escasez deben responder a una racionalidad, ser públicas y dimensionarse en toda su complejidad económica, social y ambiental para cada realidad en la que han de ser aplicadas.

15 La Corte Constitucional de Colombia, en su sentencia T-244/1994, ha entendido que la distribución inequitativa de porcentajes del caudal de agua importa un menoscabo a los principios de igualdad y no discriminación, debiendo ajustarse tales porcentajes a las necesidades básicas de los usuarios a efectos de permitir un acceso en igualdad de oportunidades. 
Eso es lo que ha ocurrido en Mendoza, por ejemplo, con toda claridad aunque fácilmente puede constatarse en otros sitios, con la declaración de caducidades para una posterior asignación, la aplicación de criterios diversos a la jerarquía definitiva/eventual o la relativa diferenciación práctica entre la concesión y el permiso para la distribución de las aguas, tanto como con la ilusoria expropiación de usos prioritarios en favor de usos preferentes ${ }^{16}$.

En este contexto, el derecho de aguas ha ido evolucionando hacia un auténtico estado de excepción, donde la aplicación constante de los mecanismos previstos por la legislación para administrar la escasez extraordinaria ha "ordinarizado" situaciones que el ordenamiento entendía excepcionales, como ocurre por ejemplo con la cotidiana distribución por "turnos" o la equiparación de las concesiones eventuales y definitivas en todo momento, incluso en periodos de emergencia hídrica.

En definitiva, se vislumbra una crisis de eficacia de los institutos clásicos para enfrentar la sequía, donde el carácter excepcional de la situación de una escasez que no es tal ya no puede servir como justificativo para la suspensión de la ley y aplicación de teóricos regímenes extraordinarios que devienen permanentes.

\section{Sequía, escasez, emergencia y excepción en el derecho de aguas}

La emergencia con fundamento en la escasez extraordinaria, es concebida normalmente como algo excepcional, que es preciso reconducir al principio o la normalidad, pero cuando la emergencia se torna permanente puede estar denotando un nuevo estado de cosas que es preciso reconocer. De allí que hay varias formas de concebir la emergencia aun cuando por espacio no tenga objeto aquí seguir profundizando en ellas más que desde su vinculación con el carácter hídrico de la misma o el estado de sequía.

En el ámbito jurisprudencial, la Corte argentina tiene un largo desarrollo de la doctrina de la emergencia, sobre todo en materia económica. Así en un comienzo sostuvo que la declaración legal de la emergencia debe ser precedida por la constatación de un estado de necesidad extrema, perseguir una finalidad legítima de interés general, ser razonable y ser ineludiblemente limitada en el tiempo (CSJN, Avico c/ De la Pesa, 1934 Fallos: 172:34).

La Corte advirtió que la prolongación de la emergencia sin límite de tiempo o su asidua reiteración de modo que la normalidad quede reducida a un interregno entre dos emergencias genera un desplazamiento del sentido común y constituye un atentado a la seguridad

$\overline{16}$ Ver por todos para el caso de Mendoza, CANo 1967. 
jurídica (CSJN, Russo, Ángel, 1959) ${ }^{17}$. Sin embargo, luego admitió el no establecimiento de un plazo, supeditando la duración de la misma a la subsistencia de la necesidad (CSJN, Peralta, L., 1990 Fallos: 313:1513). Consistentemente la Suprema Corte de Mendoza ha señalado: "[...] Se ha incurrido en la doctrina de la emergencia, a punto tal que, entre la normalidad y la anormalidad constitucionales, no sabemos bien cuál es el principio y cuál la excepción" (L.S. 300-91, voto Dr. Jorge Nanclares).

La temporalidad de la emergencia parece un requisito ineludible de la misma aunque su supeditación a la prolongación de la necesidad constituya el preanuncio de un estado de excepción. De allí que el art. 314 del CAg chileno, que sirve de ejemplo, aunque se preocupe especialmente en limitar a seis meses improrrogables la declaración de zona de escasez, no resuelve qué hacer si la necesidad se prolonga.

La tesis propuesta, en definitiva, es que el derecho de aguas de algunos sitios establece vía excepción una emergencia permanente que suspende total o parcialmente la legalidad, habilitando -como veremos a continuación- una esfera de absoluta discrecionalidad de la autoridad. Esta situación conlleva la necesidad de replantear algunos presupuestos de tales regímenes y sus instituciones a efectos de regular como ordinarias situaciones que han dejado de ser extraordinarias.

1. El contenido de la excepción en las declaraciones de emergencia o escasez hídrica extraordinaria ${ }^{18}$

a) Excepción a las formas de contratación y gasto. En el derecho argentino, la emergencia hídrica ha sido utilizada para exceptuar el principio de licitación pública, como lo prueba la legislación de Catamarca ${ }^{19}$

\footnotetext{
17 Rossati 2002, 21.

18 El inc. 9 de la declaración del Estado de Emergencia hídrica del Estado de California, de 17 de enero de 2014 dispone: 9. The Department of Water Resources and the Water Board will take actions necessary to make water immediately available, and, for purposes of carrying out directives 5 and 8, Water Code section 13247 and Division 13 (commencing with section 21000) of the Public Resources Code and regulations adopted pursuant to that Division are suspended on the basis that strict compliance with them will prevent, hinder, or delay the mitigation of the effects of the emergency. Department of Water Resources and the Water Board shall maintain on their websites a list of the activities or approvals for which these provisions are suspended.

19 Ley No 4839 de 31 de mayo de 1995 de la Provincia de Catamarca (Dec. No 894/95) Art. 1. Declárase el Estado de Emergencia Hídrica en todo el territorio de la Provincia de Catamarca a partir de la promulgación de la presente Ley y hasta tanto se modifique la situación imperante; Art. 2. Autorízase al Poder Ejecutivo a solicitar ayuda económica en el plano nacional o internacional, pudiendo firmar convenios de asistencia técnica y/o financiera a los fines de superar la situación declarada por el Artículo $1^{\circ}$; Art. 3 . Autorízase en carácter de Emergencia al Poder Ejecutivo de la Provincia a contratar servicios, obras - provisiones en forma directa hasta la suma de Pesos Ochocientos Mil (\$ 800.000), y mediante concurso de precios, hasta la suma de Pesos Un Millón Quinientos Mil (\$1.500.000), debiendo asegurarse la participación amplia de oferentes. En todos los casos
} 
o Chaco ${ }^{20}$, por ejemplo, al habilitar la contratación directa y el concurso de precios.

La prórroga de la emergencia hídrica también se erige en una constante del derecho público provincial. Si bien la primera declaración es de carácter legislativo, las prórrogas suelen efectuarse por decreto del Ejecutivo ad referendum del legislativo como ha ocurrido por ejemplo en Mendoza (Dec. N 2090/13) ${ }^{21}$.

b) Excepción a las formas de distribución del agua. Es notable el contenido que el derecho chileno ha dado a la emergencia hídrica ${ }^{22}$. En la misma se observan tres rasgos que calzan de manera muy ajustada en la hipótesis que se plantea.

se efectuarán publicaciones y las ofertas se presentarán en sobres cerrados con apertura en acto público; Art. 4. Las ofertas serán evaluadas por una comisión de Adjudicación designada por el Poder Ejecutivo, bajo la vigilancia de una Comisión Bicameral ad hoc integrada por dos senadores y dos diputados elegidos por sus respectivas Cámaras.

20 Fue la Administración Provincial del Agua (APA) la que tramitó la prórroga de la Emergencia Hídrica por Sequía, entendiendo que continúa la situación que motivara el dictado del Decreto 553/05, prorrogado en forma sucesiva por similares instrumentos legales, el último de ellos el 1658/11, cuya vigencia finalizó el 31 de diciembre de 2011. Ante esta realidad, se aplicará los alcances del art. 132, inc. D de la Ley 4787 de Administración Financiera, por el cual se podrán efectuar en forma directa las contrataciones encuadradas en cualquiera de las tipificaciones que se detallan a continuación. Así, el inciso mencionado detalla "la atención de situaciones derivadas de casos fortuitos o fuerza mayor, provocados por epidemias, inundaciones, siniestros o fenómenos geológicos o meteorológicos no previsibles que justifiquen urgencia absoluta en las contrataciones o adquisiciones".

21 Art. 1. Prorróguese en todos sus términos la vigencia del Decreto-Acuerdo № 2379/10 con las modificaciones introducidas por los Decretos-Acuerdos Nros. 90/12 y 2050/12 a fin de afrontar las consecuencias perjudiciales que pudieran derivarse de la escasez de agua superficial para el ciclo hidrológico 2013/2014.

22 Por ej. La declarada para la Región del Maule, Dec. MOP 155 de 27 de febrero de 2014, con vencimiento 27 de agosto de 2014 para las comunas de: San Clemente, Pelarco, Río Claro, San Rafael, Talca, Maule, Colbún, Yerbas Buenas, Villa Alegre, Linares y Longaví): "2. En virtud de esta declaración, y no habiendo acuerdo entre los usuarios para redistribuir las aguas, la DGA podrá hacerlo respecto de las aguas disponibles en las fuentes naturales, con el objeto de reducir al mínimo los daños generales derivados de la sequía. Igualmente, podrá suspender las atribuciones de las Juntas de Vigilancia, como también los seccionamientos de las corrientes naturales que estén comprendidas dentro de la zona de escasez hídrica; 3. La DGA podrá autorizar extracciones de aguas superficiales o subterráneas desde cualquier punto, por el mismo periodo señalado en el numeral primero de este decreto, sin necesidad de constituir derechos de aprovechamiento de aguas y sin la limitación del caudal ecológico mínimo establecido en el art. 129 bis 1 del Código de Aguas. También podrá otorgar cualquiera de las autorizaciones señaladas en el Título I del Libro Segundo de la mencionada codificación; 4. Asimismo, en las corrientes naturales o en los cauces artificiales en que aún no se hayan constituido organizaciones de usuarios, la DGA podrá a petición de parte, hacerse cargo de la distribución en las zonas declaradas de escasez; 5 . Para los efectos señalados en los numerales anteriores, la DGA adoptará las medidas necesarias sin sujeción a las normas establecidas en el Título I del Libro Segundo del Código de Aguas; 6. Esta declaración de zona de escasez no será aplicable a las aguas acumuladas en embalses particulares". 
i. La primera es el rango de la norma excepcionadora de la ley, esto es, decreto presidencial, que es autorizado por el propio art. 314 del CAg. Si bien se trata de una facultad delegada por ley, es el Ejecutivo el que en definitiva decide la excepción a la norma a través de la suspensión de su aplicación. El derecho argentino es un buen ejemplo de cómo el mecanismo excepcional del DNU previsto por la Constitución Nacional ha devenido en el mecanismo ordinario de producción normativa configurando un estado de excepción por antonomasia ${ }^{23}$.

ii. El segundo de los rasgos es que al menos a juzgar por la información disponible las declaraciones de escasez hídrica desde el 2008 en la zona central del país y sin entrar en detalle parecen una constante o al menos habilitan la pregunta ¿cuán excepcional es la escasez? Solo en lo que va del 2014 alcanza ocho declaraciones ${ }^{24}$.

iii. La tercera nota es el contenido de la emergencia, llamando notoriamente la atención por su amplitud y fuerte contenido excepcionador. La misma refiere a:

a) De no haber acuerdo entre los usuarios la DGA podrá redistribuir las aguas. Y para ello podrá suspender tanto las atribuciones de la Junta de Vigilancia como el seccionamiento de los ríos.

b) La DGA podrá autorizar extracciones de aguas superficiales y subterráneas sin necesidad de constituir derechos de aprovechamiento / sin limitación de caudal ecológico

c) La DGA adoptará las medidas necesarias sin sujeción a las normas establecidas en el Título I del Libro Segundo del Código de Aguas (Procedimientos, constitución de derechos; bocatomas; cambio de fuente; etc.)

d) Efecto inmediato de resoluciones de la DGA, sin perjuicio de la posterior toma de razón por la Contraloría General de la República.

2. La excepción reglamentaria sin fundamento en la emergencia producto de la sequía, sino en el desbalance crónico entre oferta y demanda

El supuesto que se analiza en este apartado contempla la excepción a las reglas ordinarias de acceso al agua basada también en situaciones de escasez, aunque en este caso tal carestía no resulta natural, propia de un ciclo hidrológico seco extraordinario, sino más bien eco-

\footnotetext{
23 Pérez Hualde 2005, 1.

24 Decretos $N^{\circ} 18$ de enero de 2014, N 139 de 6 de junio de 2014, N¹47 de 13 de febrero de 2014, N $N^{\circ} 154$ de 27 de febrero de 2014, N 155 de 27 de febrero de 2014, N²35 de 10 de abril de 2014, Nº 252 de 15 de abril de 2014, Nº 258 de 25 de abril de 2014.
} 
nómica, causada por problemas de desbalance entre la oferta natural y la demanda consuntiva que implican los derechos otorgados.

En estos casos, el régimen concesional habitual queda suspendido frente a reglas de excepción, que en ocasiones adquieren carácter estable ${ }^{25}$, y aunque la ratio iuris no es una emergencia de tipo climática -sequía-, es en cambio una emergencia de tipo antrópica -sobreexplotación-, que incluso puede agravarse en épocas de sequía ${ }^{26}$.

Un ejemplo de este fenómeno lo constituye el régimen de áreas de restricción para nuevas perforaciones adoptado en Mendoza de manera reglamentaria o el contemplado expresamente por la legislación española para el caso análogo ${ }^{27}$.

25 En los casos que analizaremos a continuación, esta estabilidad puede verse en la vigencia del régimen restrictivo en las aguas subterráneas de Mendoza desde 1997 o del Código de San Juan desde 1978.

${ }^{26}$ La jurisprudencia argentina (Mendoza) ha utilizado la emergencia hídrica e incluso su reiterada prórroga como argumento genérico para la justificación de un orden excepcional de cosas o de competencias extraordinarias en áreas de restricción creadas por problemas de sobreexplotación: "Paralelo con lo anterior, no se puede pasar por alto que la legislatura provincial, mediante Ley 8318 (B.O.: 20-7-2011, antes había sido decretada ad referéndum por el Poder Ejecutivo), declaró la emergencia hídrica en todo el territorio provincial, para el período hidrológico 2010-2011, a fin de aminorar los efectos esperables ante los bajos niveles de escurrimientos de los ríos (a consecuencia del escaso nivel de precipitaciones níveas ocurrido durante el invierno del 2010), según lo informado por el DGl, cuya competencia en la materia no es objeto de debate. Entre las medidas de mitigación se instruyó al D.G.I. para que distribuya el agua "ajustadamente a la oferta, a la demanda, a los usos empadronados y a las prioridades legales" (art. 6, decreto acuerdo 2379/2010, anexo de la ley). Asimismo, se procuró tanto "la utilización del agua subterránea en los diferentes usos para compensar el déficit de agua superficial", como el incremento, al máximo, del "reuso de efluentes de origen doméstico, industrial y agrícola" (art. 5). El estado de emergencia hídrica ha sido prorrogado para el ciclo hidrológico que se extiende hasta el 30 de setiembre de 2012, por Decreto Acuerdo 90/12; para el ciclo hidrológico que abarca hasta el 30 de setiembre de 2013, mediante Decreto Acuerdo 2050/12; y para el ciclo hidrológico 2013/2014, por Decreto Acuerdo 2090/13, todos ad referéndum de la H. Legislatura Provincial, y cuya ratificación cuenta con media sanción de la H. Cámara de Diputados". Suprema Corte de Justicia de Mendoza, in re Gualtallary SA c/ DGI p/ Acción de Inconstitucionalidad (2014).

27 De nuevo, la necesidad y la urgencia habilitan competencias excepcionales en la Ley 11/2012, de 19 de diciembre, que entre las medidas urgentes en materia de medio ambiente contempla la reforma del art. 56 del texto refundido de la ley de aguas española. Art. 56. Masas de agua subterránea en riesgo de no alcanzar el buen estado cuantitativo o químico.

«1. La Junta de Gobierno, sin necesidad de consulta al Consejo del Agua, podrá declarar que una masa de agua subterránea está en riesgo de no alcanzar un buen estado cuantitativo o químico, en este caso, se llevarán a cabo las siguientes medidas: a) En el plazo de seis meses, el Organismo de cuenca constituirá una comunidad de usuarios si no la hubiere, o encomendará sus funciones con carácter temporal a una entidad representativa de los intereses concurrentes. b) Previa consulta con la comunidad de usuarios, la Junta de Gobierno aprobará en el plazo máximo de un año, desde que haya tenido lugar la declaración, un programa de actuación para la recuperación del buen estado de la masa de agua, que se incluirá en el programa de medidas a que hace 
La declaración de un área de restricción (terminología del derecho argentino) o la declaración de un acuífero como sobreexplotado (derecho español) equivale a una prohibición total o parcial de realización de nuevas perforaciones o bombeo. En el caso de Mendoza, por ejemplo, el art. 23 de la Ley de Aguas Subterráneas autoriza a la autoridad de aplicación a establecer turnos, restringir, limitar o regular por resolución fundada, el uso o la extracción de agua subterránea, cuando a causa de ello puede alterarse el equilibrio del balance hidrológico del acuífero, sea por descenso de niveles, desmejoramiento en la calidad de sus aguas o por cualquier otra causa. Bajo esta norma, la Res. 673/97 HTA regula las condiciones técnicas requeridas para declarar un área de prohibición o restricción para la construcción de perforaciones, pero a la vez habilita un estado de excepción en cuanto al sistema de otorgamiento de derechos que viola abiertamente los principios legales para su otorgamiento.

La norma de carácter reglamentario dispone que declarada el área de prohibición temporaria para la construcción de perforaciones, solo

referencia el art. 92 quáter. Hasta la aprobación del programa de actuación, se podrá adoptar las limitaciones de extracción así como las medidas de protección de la calidad del agua subterránea que sean necesarias como medida cautelar.

2. El programa de actuación ordenará el régimen de extracciones para lograr una explotación racional de los recursos con el fin de alcanzar un buen estado de las masas de agua subterránea, y proteger y mejorar los ecosistemas asociados, para lo cual podrá, entre otras medidas: a) Establecer la sustitución de las captaciones individuales preexistentes por captaciones comunitarias, transformándose, en su caso, los títulos individuales con sus derechos inherentes, en uno colectivo que deberá ajustarse a lo dispuesto en el programa de actuación. b) Prever la aportación de recursos externos a la masa de agua subterránea, en ese caso incluirá los criterios para la explotación conjunta de los recursos existentes en la masa y de los externos. c) Incluir un perímetro en el cual no será posible el otorgamiento de nuevas concesiones de aguas subterráneas a menos que los titulares de las preexistentes estén constituidos en comunidades de usuarios, de acuerdo con lo dispuesto en el capítulo IV del Título IV y teniendo en cuenta lo previsto en la disposición adicional séptima. d) Determinar perímetros de protección de las masas de agua subterránea en los que será necesaria su autorización para realizar obras de infraestructura, extracción de áridos u otras actividades e instalaciones que puedan afectarla, sin perjuicio de aquellas otras autorizaciones que sean necesarias de acuerdo con la legislación sectorial de que se trate. Tal delimitación y condiciones vincularan en la elaboración de los instrumentos de planificación así como en el otorgamiento de las licencias, por las Administraciones públicas competentes en la ordenación del territorio y urbanismo.

3. El programa de actuación contemplará las condiciones en las que temporalmente se puedan superar las limitaciones establecidas, permitiendo extracciones superiores a los recursos disponibles de una masa de agua subterránea cuando esté garantizado el cumplimiento de los objetivos medioambientales.

4. Cuando como consecuencia de la aplicación del programa de actuación se mejore el estado de la masa de agua subterránea, el organismo de cuenca, de oficio o a instancia de parte, podrá reducir progresivamente las limitaciones del programa y aumentar, de forma proporcional y equitativa, el volumen que se puede utilizar, teniendo en cuenta, en todo caso, que no se ponga en riesgo la permanencia de los objetivos generales ambientales previstos en el art. 92 y siguientes». 
pueden autorizarse nuevas concesiones en reemplazo de otra perforación en funcionamiento, con equivalencia de diámetro de caño de salida y caudal previo cegado de la misma. Cuando se trate de áreas de restricción temporaria, solo podrá autorizarse una nueva concesión en reemplazo de otra perforación en funcionamiento actual o reciente, con equivalencia de diámetro de caño de salida y caudal, previo cegado de la misma ${ }^{28}$. Bajo este reglamento, entonces, y so pretexto de la escasez, se instaura un mercado informal de aguas que tensiona el principio de inherencia y el orden de prioridades legalmente establecido para el otorgamiento de los derechos en un sistema concesional puro, ya que el acceso a nuevas perforaciones no se efectúa teniendo en cuenta la prioridad legal fijada por ley, sino el eventual acuerdo individual con un concesionario anterior para que renuncie a su derecho.

Otro supuesto de este tipo puede observarse en los arts. 123 y 129 CAg de la provincia de San Juan, donde se declaran agotados e insusceptibles de nuevas concesiones para uso agrícola a los caudales de los principales ríos de esa provincia -San Juan y Jáchal-, determinándose que los procedimientos para nuevas concesiones agrícolas, en estos casos, solo podrán ser reabiertos por disposición legal expresa, previa comprobación con certeza técnico-científica indubitable de que todas las concesiones otorgadas son atendidas con las dotaciones volumétricas correspondientes.

Sin embargo, la referida prohibición de otorgar nuevos usos agrícolas, y la fijación de un procedimiento de reapertura de procedimientos para nuevas concesiones agrícolas solo cuando exista comprobación científica de la oferta, contrasta ${ }^{29}$ con la regulación explícita de un derecho a favor de las poblaciones para que se le conceda el uso del agua pública necesaria -fijándose como mínimo un caudal de entre 150 y 300 litros por habitante y por día, debiéndose tener en cuenta para su

\footnotetext{
28 A efectos de cumplimentar tal exigencia, los interesados en obtener nuevos permisos de perforación se encuentran en la necesidad de transar informalmente con los titulares de tales perforaciones, a efectos de que estos últimos renunciaran a sus derechos y autorizaran el cegado de sus perforaciones, configurándose de esta manera un mercado de derechos de pozos que se caracterizaba, no por la cesión de la concesión propiamente dicha para su uso por un nuevo titular, sino por la conformidad del anterior concesionario a la extinción de su derecho a efectos de que un nuevo peticionante pueda obtener un nuevo derecho. Con ello, en un sustrato de ausencia regulatoria, quien inicia un trámite para acceder al agua debe, necesariamente, actuar praeter legem, y realizar actos que se encuentran más allá del contenido legal, generándose antes del trámite concesional una instancia previa de negociación entre el peticionante y un tercero que detenta la titularidad de una perforación, donde acuerdan que este último brindará su voluntad de renunciar a su derecho a fin de cumplimentar la condición administrativa que permitirá el trámite del nuevo permiso de perforación y la consiguiente concesión de uso de aguas subterráneas.

${ }^{29}$ La contradicción radica, fundamentalmente, en que la fuente hídrica se considera agotada únicamente para nuevos usos agrícolas, pero se valida el trámite para solicitudes poblacionales en desmedro de la cláusula sin perjuicio de terceros.
} 
cálculo el crecimiento vegetativo probable- (art. 65 CAgSJ). Este ejemplo evidencia no solo una grave contradicción normativa, sino también la ineficacia de los institutos referidos en el punto primero de este trabajo, como el balance hidrológico, la expropiación de usos de inferior jerarquía en favor de los superiores, la cláusula sin perjuicio de terceros, etc.

\section{Conclusiones}

$1^{\circ}$ Es cada vez más frecuente ver en el ámbito del derecho de aguas declaraciones de emergencia hídrica o sequía suspendiendo la aplicación de la ley y habilitando competencias extraordinarias para la autoridad. La reiteración o prórroga de esas situaciones extiende o perpetúa el período de emergencia acentuando el fenómeno e invirtiendo el orden entre principio y excepción.

Bajo este paraguas, principio y excepción se diluyen, y cuestiones tan trascendentales como las formas normales de contratación, las reglas de distribución del agua y hasta del otorgamiento de nuevos derechos, entre otras, quedan libradas al arbitrio de la administración.

Esta gran discrecionalidad administrativa ejercida en el marco de la excepción se encuentra limitada solo por el principio de razonabilidad-nomás por el de legalidad-, y el control judicial se relaja y dificulta considerablemente cuando la misma es ejercida con fundamento en una declaración previa de emergencia hídrica o escasez, sea esta de naturaleza legal o reglamentaria.

Es necesario entonces, en primer lugar, definir, discutir y revisar a priori y cuantas veces sea necesario qué es normal u ordinario y qué es anormal o extraordinario en materia hidrológica en la actualidad y para cada lugar concreto. Cuándo puede considerarse con algún grado de objetividad y despojados de prejuicios, que estamos frente a una auténtica situación o sequía de carácter extraordinario e imprevisible, y cuándo no se trata más que de la aplicación ordinaria de un dispositivo para suspender la aplicación de la ley. Este, y no otro, debe ser el (nuevo) presupuesto del derecho de aguas en el marco de un Estado de Derecho.

$2^{\circ}$ En segundo lugar, es necesario redefinir cuáles son las reglas aptas -y con perspectivas de eficacia- para una normalidad auténtica y cuáles son las de excepción, para situaciones que realmente revistan ese carácter. Tanto en la definición de la sequía -emergencia, estado de necesidad o escasez- como en la de estas reglas, está en juego la supervivencia del Estado de Derecho y con él la de cualquier atisbo de seguridad jurídica.

El derecho de aguas contemporáneo -como el administrativo- no debe huir hacia la emergencia permanente para resolver su crisis de in- 
eficacia o la escasez de agua que es su razón de ser, sino avanzar hacia un reconocimiento de las limitaciones que los modelos clásicos rígidos de corte decimonónico evidencian con toda claridad en la actualidad, y sobre todo, de la cada vez más cambiante realidad que pretende regular.

\section{Bibliografía citada}

BIANCHI, Alberto (2002): "La emergencia desjuridiza. La emergencia absoluta, desjuridiza absolutamente", en: Debates de Actualidad, revista oficial de la Asociación Argentina de Derecho Constitucional, año XVII, № 187, abril/mayo, 20 pp.

CANo, Guillermo (1967), Reseña crítica de Legislación y Administración de Aguas en Mendoza, Mendoza, ed. del autor; Martin, L., Derecho de Aguas, Buenos Aires, Abeledo Perrot (2010).

EmBID, Irujo (2014); "Norma, Economía y Lenguaje en el derecho de la crisis económica. El control judicial de la actividad administrativa en la economía. Algunas reflexiones", en: Documentación Administrativa, Nueva Época, № 1 enero-diciembre 2014.

Gordillo, A. (2001): "El Estado de Derecho en estado de emergencia", en: La Ley, 12 de octubre de 2001.

MARTIN, Liber (2010): Derecho de Aguas. Estudio sobre el uso y dominio de las aguas públicas (Buenos Aires, AbeledoPerrot), 319 pp.

Pérez Hualde (2005): La permanente invocación de la emergencia como base de la crisis constitucional, LL Sup.Adm 2005 (diciembre), 1.

PINTO (2001): "Transformación de derechos de uso de agua eventuales en definitivos en el régimen jurídico mendocino", en: La Ley Gran Cuyo, T² 2001, La Ley, 575 pp.

PNUD (2006): Informe sobre Desarrollo Humano 2006. Más allá de la escasez: Poder, pobreza y la crisis mundial del agua (Madrid, Mundi-Prensa).

RosSATI (2002): "Decálogo para volver al sentido común", en: Debates de Actualidad, revista oficial de la Asociación Argentina de Derecho Constitucional, año XVII, $\mathrm{n}^{\circ}$ 187, Buenos Aires, abril/mayo 2002, pp. 21.

Salomoni (2002): "Interés Público y Emergencia". En Revista Actualidad en el Derecho Público, Buenos Aires, No 18-20.

Vergara Blanco (1999): "El derecho de la seguía: la redistribución de aguas", en: Revista de Derecho Administrativo Económico, Vol. I / Nº 2 - julio-diciembre 19, pp. 361-370.

Vergara Blanco (2011): Código de Aguas Comentado (Santiago, AbeloPerrot-LegalPublishing).

Wittfogel, Karl (1996): Despotismo oriental: estudio comparativo del poder totalitario (Madrid, Guadarrama).

WORSTER, Donald (1985): Rivers of Empire. Water, Aridity and Growth of the American West. (Oxford, Oxford University Press). 